\title{
DEVELOPMENT OF PARTICULATE MUCOADHESIVE GEL FOR INTRANASAL DELIVERY
}

\author{
DINANATH GAIKWAD ${ }^{1 *}$, PADMINI KURANE ${ }^{1}$, DIPAK MALI ${ }^{2}$, NAMDEO JADHAV${ }^{1}$
}

${ }^{1}$ Department of Pharmaceutics, Bharati Vidyapeeth College of Pharmacy, Kolhapur, Maharashtra, India. ${ }^{2}$ Department of Quality Assurance, Bharati Vidyapeeth College of Pharmacy, Kolhapur, Maharashtra, India. Email: gdinanath@gmail.com

Received: 21 January 2017, Revised and Accepted: 20 February 2017

ABSTRACT

Objective: The objective of this research work was to develop mucoadhesive particulates gel of propranolol hydrochloride for intranasal delivery.

Method: Drug-loaded mucoadhesive particulates were prepared by spray drying technique using polymers such as HPMC K100 and Carbopol 934P. Batches were prepared according to $3^{2}$ factorial designs.

Result: The mucoadhesive particulates prepared were evaluated for different parameters such as drug content, entrapment efficiency, mucoadhesive strength, and in vitro drug release. Infrared, X-ray powder diffraction, and differential scanning calorimetry study revealed that there was no interaction occurs between drug and excipients and confirming reduction in crystallinity. The swelling index and encapsulation efficiency were found to be $(0.9266 \%)$, (97.44\%), angle of repose, Carr's compressibility index falls in acceptable limits. At the end of 10 hrs, optimized batch showed $90.23 \%$ drug release and followed zero-order release kinetics.

Conclusion: Conclusion from the result of the studies such as increase in the concentration of polymers contributed in drug release retardation. Although the prepared formulation of nasal administration can be a value addition in treatment for heart diseases like angina pectoris, myocardial infraction.

Keywords: Mucoadhesive, Particulates, Propranolol hydrochloride, Intranasal.

(C) 2017 The Authors. Published by Innovare Academic Sciences Pvt Ltd. This is an open access article under the CC BY license (http://creativecommons. org/licenses/by/4. 0/) DOI: http://dx.doi.org/10.22159/ajpcr.2017.v10i5.17212

\section{INTRODUCTION}

Among the non-invasive routes, the nasal administration offers promising potential as a viable alternative for the delivery of some drugs [1]. In the recent years, this route has received special attention as a convenient and reliable method for the systemic delivery of drugs, especially those that are ineffective by oral route [2]. Mucoadhesive drug delivery systems have been used to improve and enhance drug bioavailability because the systems can contact with the absorption surface and prolong residence time result in a better absorption. Furthermore, reduces the frequency of drug administration due to a reduction in mucociliary clearance [3]

Several polymers, particularly hydrophilic polymers containing numerous hydrogen bond ( $\mathrm{H}$ - bond) forming groups (i.e., hydroxyl, carboxyl, amine, and amide groups) have been investigated for mucoadhesive properties. Microspheres can be described as small particles (in 1-1000 $\mu \mathrm{m}$ size range) for use as carriers of drugs and other therapeutic agents consisting of proteins or synthetic polymers which are biodegradable in nature. The term microsphere describes a monolithic spherical structure with the drug or therapeutic agent distributed throughout the matrix or encapsulated. Adhesion of drug delivery device to the mucosal membrane such as buccal, ocular, rectal, and nasal can be termed as bioadhesion [4].

Microspheric particles exhibit a prolonged residence time by intimate contact with the absorption site and produce better therapeutic action. In general, microspheric particles possess potential to be employed for targeted and controlled release of the drug, but incorporating mucoadhesive properties to particulates will furthermore improve absorption and bioavailability of the drugs. Mucoadhesive particulates used in nasal drug delivery absorb water into sphere matrix, resulting in swelling of sphere and formation of gel. The gel formation improves the nasal residential time and hence, improves consequent bioavailability.
Another mechanism stated for improving nasal bioavailability is improving the nasal permeation by opening the tight junction of the nasal epithelium. Furthermore, particulates may also protect the drug from enzymatic metabolism and sustain drug release, prolonging its effect [5].

Propranolol hydrochloride, a beta-adrenoreceptor antagonist that can acutely lower the blood pressure in human by blocking receptors nonselectively, is typically prescribed to treat hypertension, myocardial infraction, and cardiac arrhythmias. It has a short biological half-life $(3.9 \pm 0.4 \mathrm{~h})$ and the problem with the oral delivery of propranolol is its low bioavailability (26\%) due to presystemic metabolism. To overcome this problem, propranolol can be delivered via nasal route. In this work, an attempt was made to prepare gel based mucoadhesive particulates of propranolol hydrochloride to ensure satisfactory drug release in nasal cavity with the use of polymer and thereby to avoid first pass metabolism and prolong duration of action [6].

\section{MATERIAL AND METHODS}

Materials

Propranolol hydrochloride was a gift sample from IPCA Laboratories Ltd., Mumbai, India. Hydroxypropyl methylcellulose (K4M) was gifted from Colorcon Asia Pvt. Ltd, Goa. Carbopol 934P was received as gift sample from Snap Natural \& Alginate Products Ltd., Tamil Nadu. Dichloromethane and methanol were procured from Loba Chemie Pvt. Ltd. Mumbai. All the reagents were used of analytical grade.

\section{Preformulation study}

Preformulation studies on the obtained sample of drug include physical tests such as physical state, odor, color, loss on drying, determination of $\lambda \max$, and standard curve. For compatibility studies, infrared spectra of the physical mixture of the drug and the polymers and the individual drug were taken. 
Preparation of mucoadhesive particulates

In this study, mucoadhesive particulates of propranolol hydrochloride $(\mathrm{HCl})$ were prepared by spray drying technique. In this method weighed quantity of HPMC K100 and Carbopol 934P polymers was added in dichloromethane and methanol. Then, stirred this suspension and kept on the magnetic stirrer to make a homogeneous mixture. Weighed quantity of propranolol $\mathrm{HCl}$ was added to this homogeneous mixture and thoroughly mixed with a stirrer at $500 \mathrm{rpm}$. For the formation, the suspension was poured in a beaker and this was passed through the spray dryer. Three sets of particulates were prepared. In the first set, particulates of propranolol HCl were prepared using only hydroxypropyl methylcellulose K100 in different concentrations. In the second set, particulates of the drug were prepared using only Carbopol 934P in different concentrations. In the third set, particulates of the drug were prepared in a combination of polymers such as hydroxypropyl methylcellulose and Carbopol 934P [7]. The batches were prepared by $3^{2}$ factorial designs as per Table 1 .

\section{Evaluation of mucoadhesive particulates of propranolol $\mathrm{HCl}$}

\section{Drug content}

Drug content was performed to check dose uniformity in the formulation. About $50 \mathrm{mg}$ particulates were weighed and powdered. The stock solution was prepared by dissolving drug powder equivalent to $10 \mathrm{mg}$ in $10 \mathrm{ml}$ phosphate buffer $(\mathrm{pH} \mathrm{6.8).} \mathrm{Stock} \mathrm{solution} \mathrm{was}$ shaken for 20 minutes on a sonicator. This resulting solution is further diluted with phosphate buffer $(\mathrm{pH}$ 6.8) to achieve concentration up to $10 \mu \mathrm{g} / \mathrm{ml}$ and the absorbance measured at the $290 \mathrm{~nm}$ by ultraviolet (UV) spectrophotometer [8].

\section{Drug entrapment efficiency}

Particulates (50 mg) were crushed in a glass mortar, and pestle and the powdered particulates were suspended in $10 \mathrm{ml}$ phosphate buffer ( $\mathrm{pH}$ 6.8). After $24 \mathrm{hrs}$ the solution was filtered, and the filtrate was analyzed for the drug content by UV spectrophotometer at $290 \mathrm{~nm}[9,10]$.

\section{Mucoadhesion testing by in vitro wash-off test}

$100 \mathrm{mg}$ of particulates sample was placed over a nasal mucosal segment mounted on a tilted side at an angle of $45^{\circ}$. The effluent was run over the segment. The effluent was collected on a Whatman filter paper, and weight of detached particles was determined [9].

\section{In vitro release study}

The release rate of propranolol HCL from mucoadhesive particulates was determined using Franz diffusion test apparatus. The diffusion test was performed using $100 \mathrm{ml}$ of phosphate buffer $(\mathrm{pH} 6.8)$ at $37 \pm 0.5^{\circ} \mathrm{C}$ and $100 \mathrm{rpm} .5 \mathrm{ml}$ sample of diffusion medium was withdrawn from the diffusion apparatus at specific time intervals, and the withdrawn sample was replaced with fresh diffusion medium. The sample was filtered through a 0.45 membrane filter and diluted to a suitable concentration with respective diffusion medium. Absorbance of these solutions was measured at $290 \mathrm{~nm}$ wavelength using ultraviolet spectrophotometer (JascoV-630). Cumulative percentage drug release was calculated using an equation obtained from a standard curve. The drug release analyzed data were obtained using "PCP Disso V-3" software, India. To know the release mechanism of the drug from the device, the diffusion data were substituted in different kinetic equations [11,12]

\section{Fourier transform infrared spectroscopy (FTIR)}

FTIR studies were conducted to determine any possible interaction among drug and excipients used. IR absorption spectrum of propranolol $\mathrm{HCl}$ was determined by FTIR (Jasco V-530 model) using $\mathrm{KBr}$ dispersion method. Briefly, about $2 \mathrm{mg}$ of sample of was ground thoroughly with previously dried $\mathrm{KBr}$ at $120^{\circ} \mathrm{C}$ for 30 minutes; uniformly mixed with drug sample and kept in the sample holder, spectra were recorded over the wave number $400-4000 \mathrm{~cm}^{-1}$. Infrared spectrums of pure drug, a physical mixture of ingredients of the formulation, optimized batches were recorded. From the overlay spectrum analysis, the compatibility of ingredients in the formulations was found out. Pure, completely dried $\mathrm{KBr}$ was used as blank and before running the sample [9].

\section{Differential scanning calorimetry (DSC)}

Thermograms of drug and optimized formulation were obtained using DSC (Pyris Diamond TG/DTA, Make-Perkin Elmer) equipped with an intarcooler. Platinum crucible used with alpha alumina powder as a reference to calibrate the DSC temperature and enthalpy scale. The powder samples of 2-10 mg were hermetically kept in the aluminum pan and heated at a constant rate $10^{\circ} \mathrm{C}$ per minute, over a temperature range of $35-250^{\circ} \mathrm{C}$. Inert atmosphere was maintained by purging nitrogen at the flow rate of $150 \mathrm{ml} /$ minutes [13].

\section{Powder X-ray diffractometry (p-XRD)}

Optimized batch of particulates was subjected to p-XRD study using X-ray diffractometer (Philips X-ray diffractometer, PW-3710). For this, the samples of pure drug and optimized batch of the same were irradiated with monochromatized $\mathrm{CuK} \alpha$ radiation and analyzed between $10^{\circ}$ to $70^{\circ}(2 \theta)[14]$.

\section{Scanning electron microscopy (SEM)}

SEM JSM 6360 Japan has been used to determine particle size distribution, surface topography, texture and examine the morphology of fractured or sectioned surface. The same generally used for generating three-dimensional surface relief images derived from secondary electrons. The examination of polymeric drug delivery system can provide important information about the porosity and microstructure of the device [14].

\section{Accelerated stability testing}

Stability studies were conducted for a specific time period up to 15 and 30 days for selected formulations, ambient temperature, and humidity $50^{\circ} \mathrm{C} \pm 2^{\circ} \mathrm{C} / 75 \% \mathrm{RH} \pm 5 \% \mathrm{RH}$ in stability chamber for 15 and 30 days. After 15 and 30 days' sample were removed and characterized for $\%$ drug content and cumulative \% release of optimized batch [15].

\section{RESULT AND DISCUSSION}

\section{Preformulation study}

The sample of propranolol hydrochloride was found to be white, odorless, and crystalline powder. The melting point of propranolol hydrochloride was found to be in the range of $161-164^{\circ} \mathrm{C}$. The spectrum of pure propranolol $\mathrm{HCl}$ showed characteristic peaks at $1106 \mathrm{~cm}^{-1}$

Table 1: Formulation design of mucoadhesive particulates

\begin{tabular}{|c|c|c|c|c|c|}
\hline Batch No & HPMC K100 (mg) & Carbopol 934P (mg) & Dichloromethane (ml) & Methanol (ml) & Drug (Propranolol HCL) in $\mathrm{mg}$ \\
\hline F1 & 200 & 200 & 50 & 100 & 100 \\
\hline $\mathrm{F} 2$ & 200 & 300 & 60 & 120 & 100 \\
\hline F3 & 200 & 400 & 70 & 140 & 100 \\
\hline F4 & 300 & 200 & 60 & 120 & 100 \\
\hline F5 & 300 & 300 & 70 & 140 & 100 \\
\hline F6 & 300 & 400 & 80 & 160 & 100 \\
\hline F7 & 400 & 200 & 70 & 140 & 100 \\
\hline F9 & 400 & 400 & 90 & 180 & 100 \\
\hline
\end{tabular}


Table 2: Physical properties of particulates

\begin{tabular}{lllllll}
\hline Batch no & Bulk density* & Tapped density* & Hausner's ratio* & Carr's index & Angle of repose* & Drug content* \\
\hline F1 & $0.725 \pm 0.005$ & $0.818 \pm 0.020$ & $1.12 \pm 0.005$ & $11.36 \pm 0.020$ & $32.53 \pm 0.005$ & $96.34 \pm 0.010$ \\
F2 & $0.783 \pm 0.001$ & $0.903 \pm 0.120$ & $1.15 \pm 0.023$ & $13.36 \pm 0.020$ & $33.38 \pm 0.011$ & $97.01 \pm 0.005$ \\
F3 & $0.728 \pm 0.150$ & $0.843 \pm 0.010$ & $1.15 \pm 0.150$ & $13.64 \pm 0.005$ & $34.56 \pm 0.210$ & $97.53 \pm 0.013$ \\
F4 & $0.695 \pm 0.230$ & $0.738 \pm 0.230$ & $1.06 \pm 0.003$ & $5.82 \pm 0.013$ & $33.66 \pm 0.003$ & $95.17 \pm 0.020$ \\
F5 & $0.774 \pm 0.421$ & $0.813 \pm 0.150$ & $1.05 \pm 0.310$ & $4.79 \pm 0.001$ & $32.52 \pm 0.120$ & $96.30 \pm 0.005$ \\
F6 & $0.666 \pm 0.010$ & $0.766 \pm 0.300$ & $0.10 \pm 0.010$ & $13.05 \pm 0.003$ & $36.86 \pm 0.001$ & $94.00 \pm 0.001$ \\
F7 & $0.702 \pm 0.520$ & $0.742 \pm 0.010$ & $1.06 \pm 0.005$ & $14.28 \pm 0.120$ & $38.30 \pm 0.005$ & $95.71 \pm 0.004$ \\
F8 & $0.733 \pm 0.320$ & $0.830 \pm 0.050$ & $1.13 \pm 0.030$ & $13.61 \pm 0.200$ & $34.87 \pm 0.031$ & $97.51 \pm 0.010$ \\
F9 & $0.810 \pm 0.125$ & $0.940 \pm 0.240$ & $1.16 \pm 0.120$ & $12.34 \pm 0.130$ & $33.66 \pm 0.004$ & $98.03 \pm 0.020$ \\
\hline
\end{tabular}

*Indicates average \pm standard deviation $(\mathrm{n}=3)$

(C-O stretching); $1452 \mathrm{~cm}^{-1} \mathrm{C}=\mathrm{C}$ (aromatic stretching); $1267 \mathrm{~cm}^{-1}$ (C-N stretching); $1158 \mathrm{~cm}^{-1}$ (C-O stretching); and $1399 \mathrm{~cm}^{-1}\left(\mathrm{CH}_{3}\right.$ bending). Loss on drying of the sample was not more than $0.5 \%$. The $\lambda$ max of propranolol $\mathrm{HCl}$ in water was found out to be $290 \mathrm{~nm}[10,16]$.

\section{Evaluation of mucoadhesive system of propranolol HC}

Bulk density may influence flow property, porosity, dissolution, and other properties and depends on the particle size, shape and tendency of particles to adhere together. The bulk density of particulates was found between $0.441 \pm 0.011$ and $0.660 \pm 0.025 \mathrm{~g} / \mathrm{cm}^{3}$. This indicates good packing capacity of particulates. Carr's index evaluated interparticulate cohesive properties with the angle of repose measurements, studied the effects of packing geometry of solids with bulk, and tapped density. Bulk density and tapped density measurements found that density of a powder depends on particle packing and that density changes as the powder consolidate. Carr's index was found between 4.79 and 14.28. Hausner's ratio is a simple method to evaluate the stability of powder column and to estimate flow properties. Low range was observed for Hausner's ratio that indicates good flowability. Many different types of angular properties have been employed to assess flowability. Angle of repose is suited for particles $>150 \mathrm{~m}$. Values of angle of repose $\leq 30^{\circ}$ generally indicate the free-flowing material and angle of repose $\geq 40^{\circ}$ suggest a poor flowing material. The angle of repose of all the formulations fell within the range of $23.86 \pm 0.20-31.1 \pm 0.2$. The observed results suggest good flowability of the particulates. Drug content was in the range of $94.00 \pm 0.001-98.03 \pm 0.020$ indicating good content uniformity in the prepared formulation [12-15]. Physical properties of propranolol $\mathrm{HCl}$ mucoadhesive particulates are shown in Table 2.

\section{Percent moisture content}

In the formulation of mucoadhesive particulates of propranolol $\mathrm{HCl}$, polymers such as sodium alginate, HPMC K100, and Carbopol 934P are used. From swelling study, it is observed that particulates prepared with the highest HPMC K100 and Carbopol 934P concentration shows the highest swelling rate [15]. Increase in concentration of polymer in the formulation increases percent water absorption in the formulation. The moisture absorption ranges from $61.33 \pm 0.005$ to $92.66 \pm 0.005$ shown in Table 3.

\section{Drug entrapment efficiency}

The drug entrapment efficiency of all the formulations was in the range between $92.00 \%$ and $99.06 \%$. The results of drug entrapment efficiency are shown in Table 4. Drug entrapment efficiency of particulates increases with increase in the concentration of HPMC K100 and Carbopol 934P. From the results, HPMC K100 is having better entrapment efficiency than Carbopol 934P, so the formulation of particulates having HPMC K100 shows higher entrapment efficiency.

\section{Mucoadhesion testing by in vitro wash-off test}

Prepared mucoadhesive particulates were found good mucoadhesive strength. Particulates are evaluated for mucoadhesive strength in phosphate buffer (pH 6.8). The percent mucoadhesion of batch F9 was found to be good, maximum particulates adhere for a long time. As the concentration of mucoadhesive polymers increases adhesion time
Table 3: Percent moisture absorption

\begin{tabular}{ll}
\hline Batch no & \% Moisture absorption* \\
\hline F1 & $61.33 \pm 0.005$ \\
F2 & $66.66 \pm 0.005$ \\
F3 & $72.00 \pm 0.001$ \\
F4 & $78.66 \pm 0.005$ \\
F5 & $81.66 \pm 0.011$ \\
F6 & $83.33 \pm 0.011$ \\
F7 & $87.00 \pm 0.010$ \\
F8 & $90.66 \pm 0.005$ \\
F9 & $92.66 \pm 0.005$ \\
\hline
\end{tabular}

*Indicates average \pm standard deviation $(\mathrm{n}=3)$

Table 4: Drug entrapment efficiency

\begin{tabular}{ll}
\hline Batch no & \% Entrapment efficiency* \\
\hline F1 & $92.00 \pm 0.030$ \\
F2 & $96.00 \pm 0.005$ \\
F3 & $96.74 \pm 0.005$ \\
F4 & $97.50 \pm 0.030$ \\
F5 & $99.06 \pm 0.050$ \\
F6 & $96.06 \pm 0.003$ \\
F7 & $98.66 \pm 0.005$ \\
F8 & $96.34 \pm 0.005$ \\
F9 & $97.44 \pm 0.001$ \\
\hline
\end{tabular}

*Indicates average \pm standard deviation $(\mathrm{n}=3)$

also increases. Mucoadhesive strength of all formulations in phosphate buffer (pH 6.8) is shown in Tables 5 and 6.

\section{In vitro drug release studies}

The drug release from different formulation was studied using a Franz diffusion cell, which has lesser liquid capacity mimicking nasal compartment. Accurately weighed propranolol HCL loaded (100 mg) was placed on the cellophane membrane in the donor compartment containing phosphate buffer $\left(\mathrm{pH}\right.$ 6.8) maintained at $37 \pm 1^{\circ} \mathrm{C}$. The samples were withdrawn at predetermined intervals, and fresh phosphate buffer was replaced up to $10 \mathrm{hr}$. Further to determine the concentration of propranolol HCL, the samples were sent for UV spectrophotometer studies. Tables 7 and 8 show percent cumulative release of the drug.

\section{Treatment of diffusion data with different kinetic equations}

Diffusion study was conducted using Franz diffusion apparatus. The study was conducted in $900 \mathrm{ml}$ phosphate buffer ( $\mathrm{pH}$ 6.8) for first $10 \mathrm{~h}$. The drug release data were fitted to models representing zero-order (cumulative amount of drug released vs. time), firstorder (log percentage of drug unreleased vs. time), Higuchi's (cumulative percentage of drug released vs. square root of time), and Korsmeyer's equation (log cumulative percentage of drug released vs. time) kinetics to know the release mechanisms. The three parameters n-release exponent, k-release rate constant, and r-correlation coefficient were used to study the release mechanism. 
Table 5: Percent mucoadhesive strength in phosphate buffer (pH 6.8)

\begin{tabular}{lllll}
\hline Time (hours) & F1 & F2 & F3* & F4* \\
\hline 1 & $96.21 \pm 0.34$ & $97.06 \pm 0.38$ & $98.07 \pm 0.55$ & $98.47 \pm 0.54$ \\
2 & $95.21 \pm 0.78$ & $96.00 \pm 0.12$ & $94.32 \pm 0.33$ & $96.33 \pm 0.44$ \\
3 & $93.23 \pm 0.9$ & $95.43 \pm 0.47$ & $91.65 \pm 0.29$ & $93.06 \pm 0.77$ \\
4 & $91.98 \pm 0.76$ & $94.55 \pm 0.23$ & $85.34 \pm 0.06$ & $91.13 \pm 0.16$ \\
5 & $89.18 \pm 0.83$ & $93.87 \pm 0.78$ & $82.29 \pm 0.08$ & $87.44 \pm 0.69$ \\
6 & $85.76 \pm 0.93$ & $92.19 \pm 0.20$ & $79.05 \pm 0.59$ & $84.55 \pm 0.90$ \\
7 & $84.23 \pm 0.90$ & $91.78 \pm 0.48$ & $78.00 \pm 0.74$ & $83.33 \pm 0.41$ \\
8 & $83.13 \pm 0.45$ & $90.03 \pm 0.10$ & $77.55 \pm 0.98$ & $82.52 \pm 0.83$ \\
9 & $82.20 \pm 0.34$ & $89.45 \pm 0.58$ & $76.13 \pm 0.45$ & $91.03 \pm 0.79$ \\
10 & $81.34 \pm 0.69$ & $88.73 \pm 0.54$ & $75.00 \pm 0.37$ & $94.03 \pm 0.47$ \\
\hline
\end{tabular}

*Indicates average \pm standard deviation $(\mathrm{n}=3)$

Table 6: Percent mucoadhesive strength in phosphate buffer (pH 6.8)

\begin{tabular}{|c|c|c|c|c|}
\hline Time (hours) & F6* & F7* & F8* & F9* \\
\hline 1 & $99.45 \pm 0.04$ & $99.60 \pm 0.45$ & $100.1 \pm 0.37$ & $98.04 \pm 0.73$ \\
\hline 2 & $97.06 \pm 0.58$ & $97.31 \pm 0.66$ & $99.03 \pm 0.21$ & $98.39 \pm 0.03$ \\
\hline 3 & $95.02 \pm 0.29$ & $96.78 \pm 0.17$ & $98.12 \pm 0.74$ & $95.11 \pm 0.86$ \\
\hline 4 & $93.47 \pm 0.66$ & $95.34 \pm 0.40$ & $96.28 \pm 0.85$ & $91.22 \pm 0.59$ \\
\hline 5 & $93.55 \pm 0.06$ & $94.99 \pm 0.82$ & $94.29 \pm 0.87$ & $89.57 \pm 0.07$ \\
\hline 6 & $89.33 \pm 0.06$ & $93.77 \pm 0.30$ & $90.48 \pm 0.68$ & $85.66 \pm 0.97$ \\
\hline 7 & $85.06 \pm 0.79$ & $91.20 \pm 0.38$ & $88.04 \pm 0.87$ & $84.98 \pm 0.94$ \\
\hline 9 & $82.65 \pm 0.54$ & $89.45 \pm 0.58$ & $84.23 \pm 0.77$ & $81.00 \pm 0.34$ \\
\hline 10 & $81.42 \pm 0.76$ & $88.31 \pm 0.23$ & $82.65 \pm 0.40$ & $80.65 \pm 0.87$ \\
\hline
\end{tabular}

*Indicates average \pm standard deviation $(\mathrm{n}=3)$

Table 7: Percent cumulative release of F1 to F5 batches

\begin{tabular}{|c|c|c|c|c|c|}
\hline Time in hrs & F1* & F2* & F3* & F4* & F5* \\
\hline 1 & $15.33 \pm 0.03$ & $22.82 \pm 0.02$ & $28.25 \pm 0.05$ & $22.81 \pm 0.01$ & $22.81 \pm 0.01$ \\
\hline 2 & $35.13 \pm 0.05$ & $30.31 \pm 0.01$ & $33.06 \pm 0.02$ & $30.31 \pm 0.02$ & $24.04 \pm 0.02$ \\
\hline 3 & $30.71 \pm 0.01$ & $37.63 \pm 0.03$ & $38.78 \pm 0.01$ & $37.63 \pm 0.02$ & $37.61 \pm 0.05$ \\
\hline 4 & $48.64 \pm 0.05$ & $43.41 \pm 0.01$ & $43.44 \pm 0.04$ & $43.41 \pm 0.01$ & $45.13 \pm 0.01$ \\
\hline 5 & $48.64 \pm 0.01$ & $48.66 \pm 0.02$ & $47.61 \pm 0.01$ & $48.67 \pm 0.02$ & $48.63 \pm 0.02$ \\
\hline 6 & $58.21 \pm 0.05$ & $49.96 \pm 0.01$ & $56.47 \pm 0.05$ & $49.94 \pm 0.02$ & $49.93 \pm 0.01$ \\
\hline 7 & $65.81 \pm 0.01$ & $60.72 \pm 0.01$ & $60.69 \pm 0.02$ & $60.72 \pm 0.05$ & $60.73 \pm 0.02$ \\
\hline 9 & $87.41 \pm 0.02$ & $85.75 \pm 0.01$ & $87.25 \pm 0.01$ & $85.75 \pm 0.01$ & $88.74 \pm 1.07$ \\
\hline 10 & $95.62 \pm 0.01$ & $94.55 \pm 0.05$ & $94.23 \pm 0.02$ & $93.11 \pm 0.01$ & $93.07 \pm 0.01$ \\
\hline
\end{tabular}

*Indicates average \pm standard deviation $(\mathrm{n}=3)$

Table 8: Percent cumulative release of F6 to F9 batches

\begin{tabular}{lllll}
\hline $\begin{array}{l}\text { Time in } \\
\text { hour }\end{array}$ & F6* & F7* & F8* & F9* \\
\hline 1 & & & & \\
2 & $28.24 \pm 0.02$ & $15.34 \pm 0.04$ & $28.25 \pm 0.05$ & $22.82 \pm 0.02$ \\
3 & $33.05 \pm 0.02$ & $35.12 \pm 0.01$ & $33.07 \pm 0.01$ & $24.06 \pm 0.01$ \\
4 & $43.46 \pm 0.02$ & $30.72 \pm 0.02$ & $38.64 \pm 0.23$ & $37.62 \pm 0.02$ \\
5 & $47.61 \pm 0.02$ & $42.70 \pm 0.05$ & $43.46 \pm 0.02$ & $45.11 \pm 0.01$ \\
6 & $56.71 \pm 0.01$ & $58.20 \pm 0.05$ & $52.86 \pm 0.02$ & $59.94 \pm 0.03$ \\
7 & $60.73 \pm 0.01$ & $66.33 \pm 0.01$ & $60.76 \pm 0.02$ & $60.72 \pm 0.02$ \\
8 & $73.43 \pm 0.01$ & $68.55 \pm 0.02$ & $73.44 \pm 0.01$ & $73.32 \pm 0.02$ \\
9 & $86.31 \pm 0.02$ & $85.44 \pm 0.01$ & $85.81 \pm 0.05$ & $83.75 \pm 0.04$ \\
10 & $92.75 \pm 0.01$ & $92.74 \pm 0.05$ & $91.63 \pm 0.01$ & $90.23 \pm 0.01$ \\
\hline
\end{tabular}

*Indicates average \pm standard deviation $(\mathrm{n}=3)$

Observed values are given in Table 9. Regression coefficient $\left(\mathrm{r}^{2}\right)$ values of each kinetic model were compared to find out the best fit model. By comparing the $\mathrm{r}^{2}$ values of different models, zero-order model was found to be best fit, which has higher values of correlation coefficient.

In vitro diffusion data gave us information about the effect of change in polymer concentration on drug release and swelling capability of formulation. Formulation batches F1-F9 prepared by combination of HPMC K100 and Carbopol 934P polymer. Dissolution data of these all batches revealed that drug release decreases as concentration of polymers increases. From the dissolution studies of the formulations, formulation F9 was showing better drug release than other formulations with good mucoadhesion property. Hence, formulation F9 was considered as the best formulation.

\section{FTIR}

FTIR spectra confirmed that there were no any structural or chemical changes. Results in Fig. 1 showed that there exists no chemical interaction between propranolol $\mathrm{HCl}$ and excipients used in the formulation hence; these can be used in the formulation of mucoadhesive particulates of propranolol $\mathrm{HCl}$.

DSC

DSC examination was conducted for the study of the physical state of drug in the formulation. The pure drug and formulation batch F9 were evaluated. In Fig. 2, sharp melting transition of propranolol $\mathrm{HCl}$ (pure) was observed at $164.34^{\circ} \mathrm{C}$ (A curve). Same transition of propranolol HCL was observed in formulation batch F9 (B curve). The thermogram of pure propranolol $\mathrm{HCl}$ showed sharp endothermic peak starting at $160^{\circ} \mathrm{C}$ with melting peak at $164^{\circ} \mathrm{C}$ and ending at $169^{\circ} \mathrm{C}$. In the thermograms of optimized batch, endothermic peak was obtained at 
Table 9: Kinetic data of propranolol $\mathrm{HCl}$ mucoadhesive particulates

\begin{tabular}{lllll}
\hline Batch no & Zero-order (R) & First-order (R) & Matrix model (R) & Peppas model (R) \\
\hline F1 & 0.9770 & 0.8746 & 0.9518 & 0.9754 \\
F2 & 0.9672 & 0.8861 & 0.9551 & 0.9707 \\
F3 & 0.9504 & 0.8926 & 0.9608 & 0.9512 \\
F4 & 0.9683 & 0.9073 & 0.9605 & 0.9757 \\
F5 & 0.9723 & 0.9030 & 0.9536 & 0.9521 \\
F6 & 0.9486 & 0.9104 & 0.9535 & 0.9533 \\
F7 & 0.9761 & 0.9136 & 0.9560 & 0.9753 \\
F8 & 0.9456 & 0.9158 & 0.9622 & 0.9497 \\
F9 & 0.9704 & 0.9302 & 0.9595 & 0.9654 \\
\hline
\end{tabular}

Table 10: Evaluation of optimized formulation F9 after stability period

\begin{tabular}{lll}
\hline \multirow{2}{*}{ Parameters } & \multicolumn{2}{l}{ Time period } \\
\cline { 2 - 3 } & Before* & After 30 days* \\
\hline Swelling index & $0.9266 \pm 0.005$ & $0.9166 \pm 0.003$ \\
Mucoadhesion & $96.48 \pm 0.24$ & $95.47 \pm 0.22$ \\
Encapsulation & $97.44 \pm 0.01$ & $97.44 \pm 0.01$ \\
\% Drug release after 10 hrs & $90.23 \pm 0.01$ & $90.22 \pm 0.001$ \\
Drug content $(\%)$ & $98.03 \pm 0.02$ & $98.00 \pm 0.01$ \\
\hline *Indicates average \pm standard deviation $(\mathrm{n}=3)$ &
\end{tabular}

$164.34^{\circ} \mathrm{C}$. Slight shifting of endothermic peaks with a decrease in its intensity indicates amorphism of drug.

\section{p-XRD}

Powder X-ray diffraction study reveals information about the crystallographic structure and composition of materials [10,17]. Intensity of the peaks for the pure drug was sharp, but when it was incorporated into the polymer matrix, the intensities of the peaks decreases due to decreased crystallinity of the propranolol HCl. p-XRD of propranolol $\mathrm{HCl}$ and formulation batch $\mathrm{F} 9$ shows relative intensity the peaks of propranolol $\mathrm{HCl}$ have not been changed in the formulation. In the case of batch F9, the total number of peaks has been reduced due to a reduction in crystallinity of propranolol $\mathrm{HCl}$ and may be due to dilution of drug and polymers during the process.

\section{SEM}

The photographs of formulations taken by SEM are shown in Fig. 3. Particulates of propranolol $\mathrm{HCl}$ were approximately spherical or oval, and their surface was smooth giving them a good appearance. From the photographic observations in Fig. 3, it can be stated that soft and gel like nature of formulation indicated to retard the release of propranolol $\mathrm{HCl}$.

\section{Accelerated stability studies}

Stability study was conducted for the formulations at $40 \pm 1{ }^{\circ} \mathrm{C}$ and $75 \%$ $\mathrm{RH}$ for a period of 30 days. The samples were analyzed for drug content at different time intervals, and it is evident that there were slight changes in the content of drug as shown in Table 10.

For stability study, formulation batch F9 was kept for 30 days in stability chamber, and samples were taken after 30 days and analyzed for swelling index, mucoadhesion, encapsulation efficiency, drug content and \% drug release after $10 \mathrm{hrs}$, which showed slight changes. This indicates that the formulation batch F9 was stable for a period of 30 days at $40 \pm 1^{\circ} \mathrm{C}$ and $75 \% \mathrm{RH}$.

\section{CONCLUSION}

In this study, a satisfactory attempt has been done to formulate mucoadhesive particulates of propranolol HCL. From the experimental study, spray drying technique was successfully developed for formulation of sustained release mucoadhesive particulates of propranolol hydrochloride. The particulates prepared using HPMC

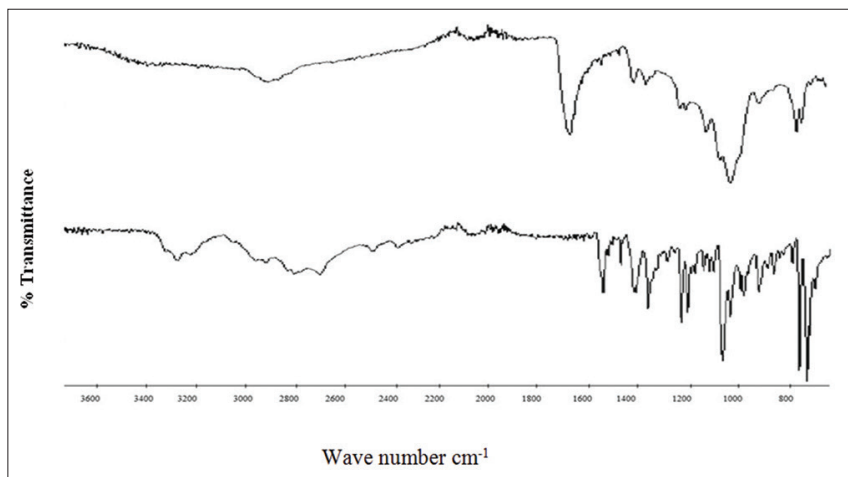

Fig. 1: Overlain spectrums of pure drug (propranolol $\mathrm{HCl}$ ) and optimized batch F9

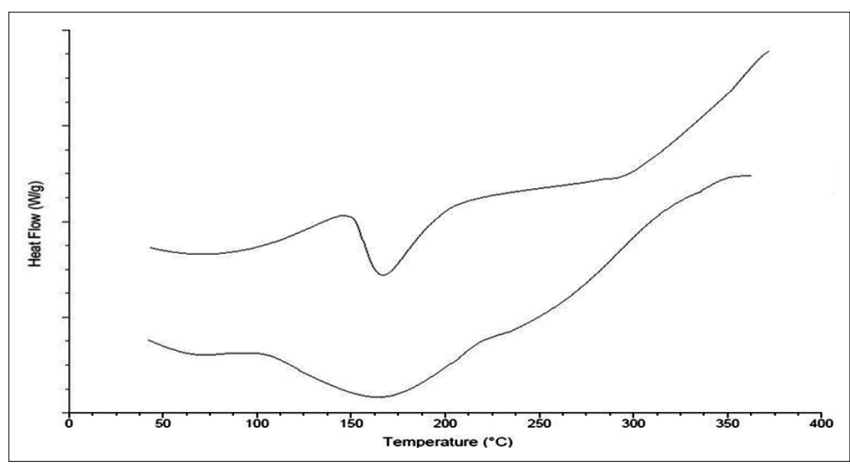

Fig. 2: Differential scanning calorimetry thermograms (a) propranolol $\mathrm{HCl}$, (b) optimized batch (F9)
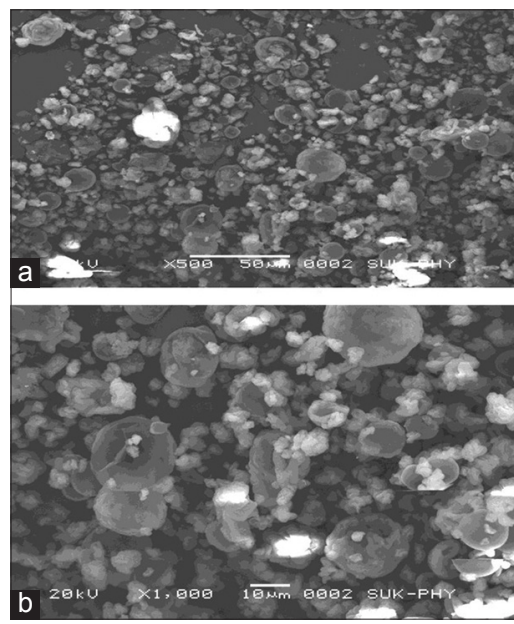

Fig. 3: (a and b) Scanning electron microscopy images of formulation batch $\mathrm{F} 9$ 
K100 and Carbopol 934P showed good results in terms of drug release, mucoadhesion strength and entrapment efficiency. It is concluded that the prepared drug delivery system containing mucoadhesive polymers can be considered as one of the promising formulation technique for preparing sustained drug delivery systems and hence, in the management of hypertensions.

\section{REFERENCES}

1. Sanjay D, Beduin M, Bhasakar M, Ananya M, Sandeepan D. Nasal drug delivery: An approach of drug delivery through nasal route. Pharm Sin 2011;2(3):94-106.

2. Dhakar R, Sheo D. A review on factors affecting the design of nasal drug delivery system. Int J Drug Deliv 2011;3(2):94-208.

3. Yadav V, Gupta AB, Raj K, Yadav J, Brajesh K. A Mucoadhesive polymers: Means of improving the mucoadhesive properties of drug delivery system. J Chem Pharm Res 2010;2(5):418-32.

4. Ranjna D, Archana C, Pandit V. Mucoadhesive in situ nasal gel - A novel approach. J Adv Drug Deliv 2014;1(6):1-8.

5. Ankita G, Prashant U. Mucoahesive microspheres: A short review. Asian J Pharm Clin Res 2012;5(3):24-7.

6. Yadav A, Jain D. Formulation and evaluation of mucoadhesive microspheres of propranolol hydrochloride for sustained drug delivery. Asian J Pharm Med Sci 2011;1(1):1-8.

7. Kumar A, Balakrishna T, Jash R, Murthy TE, Kumara A, Sudheer B. Formulation and evaluation of mucoadhesive microcapsules of metformin HCL with gum karaya. Int $\mathrm{J}$ Pharm Pharm Sci 2011;3(3):150-5
8. Velmurugan S, Ali MA. Mucoadhesive microspheres - An overview. Int J Drug Dev Res 2013;5(3):229-33.

9. Rajeshwar K, Singh B, Juyal A. Mucoadhesive microspheres of famotidine: Preparation characterization and in-vitro evaluation. Int $\mathrm{J}$ Engg Sci Tech 2010;2(6):1575-80.

10. Velmurugan S, Ali MA. Formulation and evaluation of maraviroc mucoadhesive microspheres by ionotropic gelation method. Int J Pharm Pharm Sci 2013;5:294-302.

11. Prasant R, Amitava G, Udaya N, Nayak B. Effect of method of preparation on physical properties and in vitro drug release profile of losartan microspheres - A comparative study. Int J Pharm Pharm Sci 2009;1(1):108-18

12. Desai S, Vidyasagar G, Shah V, Desa D. Preparation and in vitro characterization of mucoadhesive microspheres of midazolam: Nose to brain administration. Asian J Pharm Clin Res 2011;4(1):100-2.

13. Gangurde HH, Chavan NV, Mundada AS, Derle DV, Tamizharasi S. Biodegradable chitosan-based ambroxol hydrochloride microspheres: Effect of cross-linking agents. J Young Pharm 2011;3(1):9-14.

14. Pachuau L, Sarkar S, Mazumder B. Formulation and evaluation of matrix microspheres for simultaneous delivery of salbutamol sulphate and theophylline. Trop J Pharm Res 2008;7(2):995-1002.

15. Bamba M, Puisieux F. Release mechanism in gel forming sustained release preparation. Int J Pharm 1979;2(5-6):307-15.

16. Gohel MC, Amin AF. Formulation optimization of controlled release diclofenac sodium microspheres using factorial design. J Control Release 1998;51(2-3):115-22.

17. Dasari A, Sellappan V. Formulation and evaluation of nevirapine mucoadhesive microspheres. Int J Pharm Pharm Sci 2015;7(6):342-8. 